University of New Hampshire

University of New Hampshire Scholars' Repository

6-2002

\title{
The high-frequency backscattering angular response of gassy sediments: Model/data comparison from the Eel River Margin, California
}

\author{
Luciano E. Fonseca \\ University of New Hampshire, Durham, luciano@ccom.unh.edu \\ Larry A. Mayer \\ University of New Hampshire, larry.mayer@unh.edu \\ Dan Orange \\ AOA Geophysics \\ Neal Driscoll \\ Woods Hole Oceanographic Inst.
}

Follow this and additional works at: https://scholars.unh.edu/ccom

Part of the Oceanography and Atmospheric Sciences and Meteorology Commons

\section{Recommended Citation}

The following article appeared in: L. Fonseca, L. Mayer, D. Orange, and N. Driscoll, 'The high-frequency backscattering angular response of gassy sediments: Model/data comparison from the Eel River Margin, California', The Journal of the Acoustical Society of America, vol. 111, no. 6, p. 2621, 2002.

http://scitation.aip.org/content/asa/journal/jasa/111/6/10.1121/1.1471911

This Journal Article is brought to you for free and open access by the Center for Coastal and Ocean Mapping at University of New Hampshire Scholars' Repository. It has been accepted for inclusion in Center for Coastal and Ocean Mapping by an authorized administrator of University of New Hampshire Scholars' Repository. For more information, please contact Scholarly.Communication@unh.edu. 


\title{
The high-frequency backscattering angular response of gassy sediments: Model/data comparison from the Eel River Margin, California
}

\author{
Luciano Fonseca ${ }^{\text {a) }}$ \\ Center for Coastal and Ocean Mapping, University of New Hampshire, Durham, New Hampshire 03824 \\ and PETROBRAS/Research Center, Cidade Universitaria, Ilha do Fundao, Rio de Janeiro, \\ RJ, 21949-900, Brazil \\ Larry Mayer ${ }^{\text {b) }}$ \\ Center for Coastal and Ocean Mapping, University of New Hampshire, Durham, New Hampshire 03824 \\ Dan Orange ${ }^{\mathrm{c})}$ \\ AOA Geophysics, Marine Geoscience Division, 123 Walker Valley Road, Castroville, California 95012-9733 \\ Neal Driscolld \\ Woods Hole Oceanographic Institution, Woods Hole, Massachusetts 02543
}

(Received 25 January 2001; revised 4 December 2001; accepted 18 February 2002)

\begin{abstract}
A model for the high-frequency backscatter angular response of gassy sediments is proposed. For the interface backscatter contribution we adopted the model developed by Jackson et al. [J. Acoust. Soc. Am. 79, 1410-1422 (1986)], but added modifications to accommodate gas bubbles. The model parameters that are affected by gas content are the density ratio, the sound speed ratio, and the loss parameter. For the volume backscatter contribution we developed a model based on the presence and distribution of gas in the sediment. We treat the bubbles as individual discrete scatterers that sum to the total bubble contribution. This total bubble contribution is then added to the volume contribution of other scatters. The presence of gas affects both the interface and the volume contribution of the backscatter angular response in a complex way that is dependent on both grain size and water depth. The backscatter response of fine-grained gassy sediments is dominated by the volume contribution while that of coarser-grained gassy sediments is affected by both volume and interface contributions. In deep water the interface backscatter is only slightly affected by the presence of gas while the volume scattering is strongly affected. In shallow water the interface backscatter is severely reduced in the presence of gas while the volume backscatter is only slightly increased. Multibeam data acquired offshore northern California at $95 \mathrm{kHz}$ provides raw measurements for the backscatter as a function of grazing angle. These raw backscatter measurements are then reduced to scattering strength for comparison with the results of the proposed model. The analysis of core samples at various locations provides local measurements of physical properties and gas content in the sediments that, when compared to the model, show general agreement. (C) 2002 Acoustical Society of America.
\end{abstract}

[DOI: $10.1121 / 1.1471911]$

PACS numbers: 43.30.Gv, 43.30.Ft, 43.30.Hw [DLB]

\section{INTRODUCTION}

Fine-grained sediments from continental margins are frequently rich in bubbles of free gas (Richardson and Davis, 1998). These gas bubbles, even in very small quantities, can dominate and change the geoacoustic characteristics of seafloor sediment and have a significant effect on the propagation of acoustic waves (Lyons et al., 1996; Anderson et al., 1998; Wilkens and Richardson, 1998). Anderson et al. (1998) describe three types of bubbles in sediments, in order of increasing size and disturbance: (1) interstitial bubbles, which are very small bubbles within the undistorted interstitial pore spaces of the sediment; (2) reservoir bubbles, which

\footnotetext{
a)Electronic mail: luciano@ccom.unh.edu

b)Electronic mail: 1mayer@unh.edu

${ }^{c}$ Electronic mail: dan_orange@aoageophysics.com

${ }^{\mathrm{d})}$ Electronic mail: ndriscoll@whoi.edu
}

are a reservoir of gas occupying a region of undistorted sediment solid framework larger than the normal pore space; and (3) sediment displacing bubbles, which are bubble cavities that are larger than the normal interstitial space and that are surrounded by either undisturbed or slightly distorted sediments. While the nature of the effect on acoustic propagation will differ with the type of bubbles, in general, if gas bubbles are trapped in the sediment structure, their scattering contribution will be stronger than the contribution of other scatterers and will control the total backscattering response. In this paper, we propose a high-frequency (to $100 \mathrm{kHz}$ ) acoustic backscatter model for the seafloor that takes into account the contribution of gas bubbles and then we test the model against both multibeam sonar backscatter data and core data collected in regions known to have gassy sediments.

Traditionally, high-frequency backscatter cross-section models consider two different processes: interface scattering 
and volume scattering (Ivakin, 1998). The interface scattering occurs at the water-sediment interface, where the sea floor acts as a reflector and scatterer of the incident acoustic energy. A portion of the incident acoustic energy will be transmitted into the seafloor. This transmitted energy will be scattered by heterogeneities in the sediment structure, which are the source of the volume scatter (Novarini and Caruthers, 1998). In the approach developed in this paper we explore how that these two contributions are affected by the presence of gas.

For the interface backscatter contribution we have adopted the model developed by Jackson et al. (1986), but added modifications to accommodate gas bubbles. Interface backscatter is normally dependent on the acoustic impedance as well as the acoustic attenuation in sediments, both of which are affected by the presence of gas. The results of Anderson and Hampton (1980a, b), who modeled the influence of gas bubbles on sediment properties, will be used to estimate the changes in interface backscatter.

Models for volume scattering include refraction at the water-sediment interface and attenuation in the sediment, both of which are altered when gas is present. For the volume backscatter contribution we have developed a model based on the presence and distribution of gas in the sediment. We treat bubbles as individual discrete scatterers that integrate to create the total bubble contribution. The integration is based on the statistical distribution of bubble sizes, derived from measured histograms in muddy sediments (Anderson et al., 1998). This total bubble contribution is then added to the volume contribution of other discrete scatterers.

To test the ideas outlined above we use data collected on the highly sedimented Eel River Margin offshore northern California. The Eel River basin was extensively investigated as part of the STRATAFORM (STRATA FORmation on the Margins) project, a multiyear, multiinvestigator program funded by the U.S. Office of Naval Research (Nittrouer, 1998). During this project, an immense database of marine information was collected (Mayer et al., 1999), including multibeam sonar backscatter data collected at $95 \mathrm{kHz}$ and numerous core sampling sites with measurements of sediment physical properties and free gas content. Multibeam sonar systems map the seabed through a wide range of grazing angles, revealing subtle differences in the backscatter response for different materials on the seafloor (de Moustier and Alexandrou, 1991). In this study, multibeam-sonar raw backscatter measurements will be reduced to scattering strength for comparison with the results of the proposed model. The analysis of core data provides local measurements of physical properties and gas content that are used as input parameters for the model. The model results at the core locations are then compared to the multibeam-sonar measurement.

\section{INTERFACE BACKSCATTER}

The composite roughness model developed by Jackson et al. (1986) estimates the interface backscattering cross section $\left(\sigma_{r}\right)$ for a particular seafloor type as a function of frequency and grazing angle. It is based on a hybrid method that takes into account the Rayleigh-Rice small perturbation solution, with the local grazing angle dependent on the slope of the large-scale surface. This model defines the seafloor type based on five parameters that reflect sediment physical properties and seafloor roughness [Eq. (1)]: (a) two parameters for impedance: sound velocity ratio $(\nu)$ and density ratio $(\rho)$, (b) one parameter for attenuation: loss parameter $(\delta)$, and (c) two parameters for roughness: the spectral strength $\left(\omega_{2}\right)$ and the spectral exponent of bottom relief $(\lambda)$. The acoustic frequency $(f)$ and the grazing angle $(\theta)$ of the wave front with the seafloor are treated as given parameters. The modeling function for $\sigma_{r}$ is calculated as a combination of the Kirchhoff solution for grazing angles near vertical incidence and the composite roughness solution for other angles. The actual expression and solution for Eq. (1) can be found in Mourad and Jackson (1989):

$$
\sigma_{r}(\theta, f)=F\left(\theta, f ; \rho, \nu, \delta, \omega_{2}, \lambda\right)
$$

where $\sigma_{r}$ is the interface backscattering cross-section per unit solid angle per unit area, $\theta$ is the grazing angle, $f$ is frequency, $\rho$ is the ratio of sediment mass density to water mass density, $\nu$ is the ratio of sediment sound speed to water sound speed, $\delta$ is the loss parameter: ratio of imaginary to real wave number for the sediment, $\omega_{2}$ is the spectral strength of bottom relief spectrum $\left(\mathrm{cm}^{4}\right)$ at wave number 1 $\mathrm{cm}^{-1}$, and $\lambda$ is the spectral exponent of bottom relief spectrum.

In our approach we assume that this interface backscattering will be affected by the presence of gas bubbles in the sediment through their impact on seafloor geoacoustic properties. An extra parameter $\xi$, which is the volume fraction of free gas in the sediment, is added to the model. The model parameters most affected by the gas content are the density ratio, the sound speed ratio, and the loss parameter. While there may be large-scale features such as pockmarks or mud volcanoes (with length scales of tens to hundreds of meters) associated with gas expulsion (Hovland and Judd, 1989), these features will have little influence on the small footprints of the $95-\mathrm{kHz}$ multi-beam echo sounder. Thus, to a first approximation, we assume that the model roughness parameters will not be influenced by the presence of gas.

The interface backscattering cross section per unit solid angle per unit area $\sigma_{r}$, modified to take into account the gas content of sediments, is now dependent on six parameters:

$$
\sigma_{r}(\theta, f)=F\left(\theta, f ; \xi, \rho(\xi), \nu(\xi), \delta(\xi), \psi_{2}, \lambda\right),
$$

where $\xi$ is free gas $=$ gas volume/total sediment volume.

The influence of gas bubbles on sediments was modeled by Anderson and Hampton (1980a, b). We apply this approach to derive expressions for $\rho(\xi), \nu(\xi)$, and $\delta(\xi)$. One simplification used in this work is to consider marine sediments as water-saturated aggregates of particles with no rigid skeletal frame. In doing this, we follow the approach of Jackson and Ivakin (1998), who assume that the shear modulus of elasticity for the marine sediments is zero. This is a reasonable assumption for the upper few decimeters of unconsolidated sediments (the probable limit of penetration of a 95$\mathrm{kHz}$ sonar), especially for silt and clays (Mourad and 
Jackson, 1989). Another assumption is that the sediment volume does not change when gas is added, i.e., gas just replaces the water in the sediment body. With these assumptions, the density ratio of gassy sediment, with a volume fraction $\xi$ of free gas, will be

$$
\rho(\xi)=\frac{\rho_{s}-\xi\left(\rho_{w}-\rho_{g}\right)}{\rho_{w}}
$$

where $\rho_{g}$ is the density of the gas, $\rho_{w}$ is the density of interstitial water, and $\rho_{s}$ is the density of the gas-free water/ sediment aggregate.

The sound speed in gassy sediments is highly dependent on the resonance frequency of gas bubbles. The resonance frequency for a gas bubble of radius a, inside a water/ sediment aggregate is inversely proportional to the bubble size [Eq. (4)]:

$$
f_{0}=\frac{1}{2 \pi a}\left(\frac{3 \gamma P_{0}}{A \rho_{s}}\right)^{1 / 2}
$$

where $f_{0}$ is the resonance frequency for a gas bubble of radius a, $a$ is the bubble radius, $\gamma$ is the ratio of specific heat of the gas, $P_{0}$ is the ambient hydrostatic pressure, and $A$ is the polytropic coefficient.

The polytropic coefficient characterizes the thermodynamic process involved during bubble pulsation and the relationship between bubble volume and pressure (Anderson and Hampton, 1980a). In the range of frequencies of multibeam sonar, the full expression for the polytropic coefficient $A$ should be used [Eq. 5(a)]. The auxiliary variable $B$ of Eq. 5 (b) is the thermal damping constant:

$$
\begin{aligned}
A= & \left(1+B^{2}\right)\left(1+\frac{3(\gamma-1)}{x}\left(\frac{\sinh x-\sin x}{\cosh x-\cos x}\right)\right), \\
B= & 3(\gamma-1) \\
& \times\left(\frac{x(\sinh x+\sin x)-2(\cosh x-\cos x)}{x^{2}(\cosh x-\cos x)+3(\gamma-1)(\sinh x-\sin x)}\right),
\end{aligned}
$$

where $x=a \sqrt{2 \pi f \rho_{g} s_{p} / C_{g}}, s_{p}$ is the specific heat at constant pressure of the gas, and $C_{g}$ is the thermal conductivity of the gas.

One of the most difficult quantities to model is the distribution of gas bubble sizes. Gas bubbles in fine-grained sediments exist in a range of sizes, but have rarely been directly measured. Anderson et al. (1998) used an x-ray CT scanner to produce both a qualitative and quantitative characterization of bubble size population from cores collected in muddy sediments from Eckernfoerde Bay, on the Baltic coast. Their technique has a resolution limit of $0.42 \mathrm{~mm}$ and thus their size distribution histograms appear to be the larger bubble segment of a peaked size distribution similar to that seen for populations of bubbles in seawater near the ocean surface (Farmer and Vagle, 1989). The number of bubbles Anderson et al. (1998) observed in their sediment samples

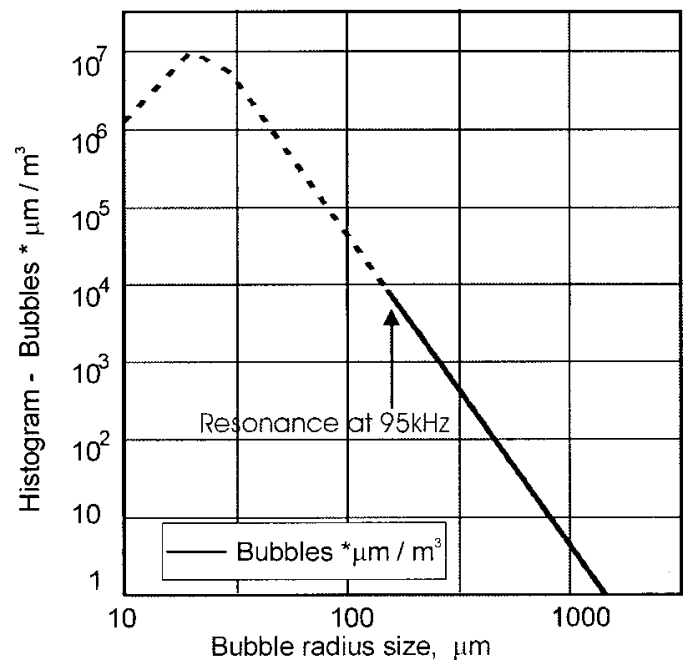

FIG. 1. Bubble size histogram. Number of bubbles per unit volume $\left(\mathrm{m}^{3}\right)$ over a bubble radius bin of $1 \mu \mathrm{m}$.

increased monotonically as bubble size decreased. Although they were unable to measure bubbles smaller than $0.42 \mathrm{~mm}$, Anderson et al. (1998) speculate that the peak in their size distribution may be near this resolution limit, but they also present circumstantial evidence (the increase in normally incident energy between 15 and $30 \mathrm{kHz}$, returned from the sediment-water interface) for the existence of very small bubble in the upper few $\mathrm{cm}$ of the sea floor. The histograms of bubble size in muddy sediments depict slightly smaller bubble sizes than those found in water due to the higher viscosity of the mud. Boyle and Chotiros (1995) used a similar histogram for bubble sizes in soft sediments. The histogram used in our examples is based on these three previous works and is normalized for a water depth of $20 \mathrm{~m}$. It follows the distribution measured by Anderson et al. for the larger bubble fraction and allows the probability of small size bubbles as discussed by Boyle and Chotiros. The minimum bubble radius used in the modeling is $180 \mu \mathrm{m}$, which is the resonance radius at $95 \mathrm{kHz}$ for the deepest part of the survey area. For bubbles larger than the minimum size, the histogram decreases monotonically with a constant slope on a $\log -\log$ graph (Fig. 1). The dashed part of the histogram was not actually used in the calculations, and shows only a probable theoretical shape for the bubble size distribution. Based on this histogram, we can define a probability density function $z(a)$ of bubble sizes:

$$
z(a)=\frac{\partial Z_{a}(a)}{\partial a}
$$

where $z$ is the probability density function of bubble sizes and $Z_{a}$ is the bubble distribution: bubbles per unit volume with radius less than $a$.

For the sound-speed ratio, we used the expression for gassy water formulated by Silberman (1957), but adapted for the case of fine-grained sediments. The bulk modulus of elasticity of the water, present in the original expression, is substituted with the bulk modulus of the gas-free water/sediment aggregate: 


$$
\nu(\xi)=\frac{c_{s}}{c_{w} \sqrt{(1 / 2)\left(1+\rho_{s} c_{x}^{2} X_{1} / \gamma P_{0}\right)\left[1 \pm \sqrt{1+\left(\rho_{s} c_{s}^{2} Y_{1} /\left(\gamma P_{0}+\rho_{s} c_{s}^{2} X_{1}\right)\right)^{2}}\right.}},
$$

where $c_{s}$ is the sound speed for the gas-free water/sediment aggregate and $c_{w}$ is the sound speed in water.

The expressions for $X_{1}$ and $Y_{1}$ are the same used by Anderson and Hampton (1980a), modified to take into account the proposed bubble distribution:

$$
\begin{aligned}
& X_{1}=\int_{a_{\text {min }}}^{a_{\text {max }}} \frac{\xi\left(1-f^{2} / f_{0}^{2}(a)\right)}{\left(1-f^{2} / f_{0}^{2}(a)\right)+d_{c}^{2}(a) f^{4} / f_{0}^{4}(a)} z(a) d a, \\
& Y_{1}=\int_{a_{\text {min }}}^{a_{\max }} \frac{d^{c}(a) f^{2} / f_{0}^{2}(a)}{\left(1-f^{2} / f_{0}^{2}(a)\right)+d_{c}^{2}(a) f^{4} / f_{0}^{4}(a)} z(a) d a,
\end{aligned}
$$

where

$$
d_{c}(a)=B+\frac{\rho_{s} a^{3} w^{3} A}{3 \gamma P_{0} c_{s}}+\frac{8 \pi f \mu A}{3 \gamma P_{0}}
$$

is the bubble damping constant and $\mu$ is the viscosity of the gas-free water/sediment aggregate.

The attenuation of sound in the aggregate is also a function of the bubble distribution (Anderson and Hampton, 1980a), and can be expressed as

$$
\alpha(\xi)=\frac{\pi f \nu(\xi) c_{w} \rho_{s}}{\gamma P_{0}} Y_{1},
$$

where $\alpha(\xi)$ is the attenuation coefficient in $\mathrm{dB} / \mathrm{m}$ for a gassy sediment.

Finally, the loss parameter is defined as the ratio of the imaginary part to the real part of the complex sediment acoustic wave number. It is related to the attenuation coefficient, the frequency, and the sound speed in the gassy sediment (Mourad and Jackson, 1989):

$$
\delta(\xi)=\frac{\alpha(\xi) \nu(\xi) c_{w} \ln (10)}{40 \pi f} .
$$

\section{VOLUME BACKSCATTER}

In areas predominantly covered with sediments, the volume scattering from subbottom sediment layers or from discrete scatters within the upper sediment layers can contribute extensively to the total backscattering cross section intensity. The model for volume scattering should include refraction at the sediment interface and attenuation in the sediment itself. On a rough seafloor, the penetration of the acoustic field in the sediment is very small for grazing angles smaller than the critical angle. This is an important issue because this reduces drastically the volume backscattering contribution for shallow grazing angles. The refracted energy will be attenuated as it travels through the sediment structure, making the attenuation coefficient a key parameter for the estimation of volume scattering.
In their approach for determining volume scatter, Jackson and Briggs (1992) consider the sediment a statistically homogeneous semi-infinite propagation medium delimited by a rough surface. With this simplification they define a volume backscattering cross section equivalent to the interface, using a similar solution to the one proposed by Stockhausen (1963). The total volume contribution is dependent on a free parameter $\sigma_{2}$, which is calculated based on the ratio of the sediment volume scattering cross section to sediment attenuation coefficient. In our proposed model, we regard the parameter $\sigma_{2}$ as a measurement of the volume contribution of general heterogeneities. Its equivalent volume scattering cross section will be added to the calculated volume scattering cross section from gas bubbles.

The scattering mechanism of bubbles in a lossy fluid was studied by Anderson and Hampton (1980b). In their formulation, the total scattering cross section of sound though a bubble screen is highly dependent on the resonance frequency of the bubbles. The actual acoustic cross section at resonance can be hundreds of times the bubble physical cross section. If we have a distribution of bubble sizes in the sediment body, we can calculate the sediment volume backscattering cross section per unit of volume, as the sum of the contribution of all individual bubbles within that volume (Boyle and Chotiros, 1995). The following expression extends the formulation of Anderson and Hampton (1980b) for the probability density function of bubble sizes of Eq. (6):

$\Sigma_{b}=\int_{a_{\min }}^{a_{\max }} \frac{a^{2}}{\left[\left(f_{0}(a) / f\right)^{2}-1\right]^{2}+\left(f_{0}(a) / f\right)^{4} d_{c}(a)^{2}} z(a) d a$,

where $\Sigma_{b}$ is the backscattering cross section for a bubble distribution.

The volume backscattering cross section of bubbles $\Sigma_{b}$ is calculated per unit of volume, as the bubble distribution accounts for number of bubbles per unit of volume. Consequently, $\Sigma_{b}$ should be scaled to reflect the volume fraction of free gas $\xi$. This scaled contribution is then added to the volume scattering cross section of other heterogeneities (other than gas bubbles), as described by the parameter $\sigma_{2}$. The total volume scattering cross section will be

$$
\sigma_{v}(\theta)=\frac{5\left(\xi \Sigma_{b}+\sigma_{2} \alpha(\xi)\right) c_{w}\left|1-R^{2}(\theta)\right|^{2} \sin ^{2}(\theta)}{40 \pi f|P(\theta)|^{2} \operatorname{Im}|P(\theta)|},
$$

where $\sigma_{v}$ is the volume backscattering cross-section equivalent to the interface, $\sigma_{2}$ is the volume scattering parameter, $R(\theta)$ is the complex reflection coefficient, and $P(\theta)$ is the complex function for the forward loss model, as defined in Mourad and Jackson (1989).

The small-scale backscattering cross section of Eq. (2), as well as the equivalent volume cross section of Eq. (12), should be averaged over the bottom slope to account for the 


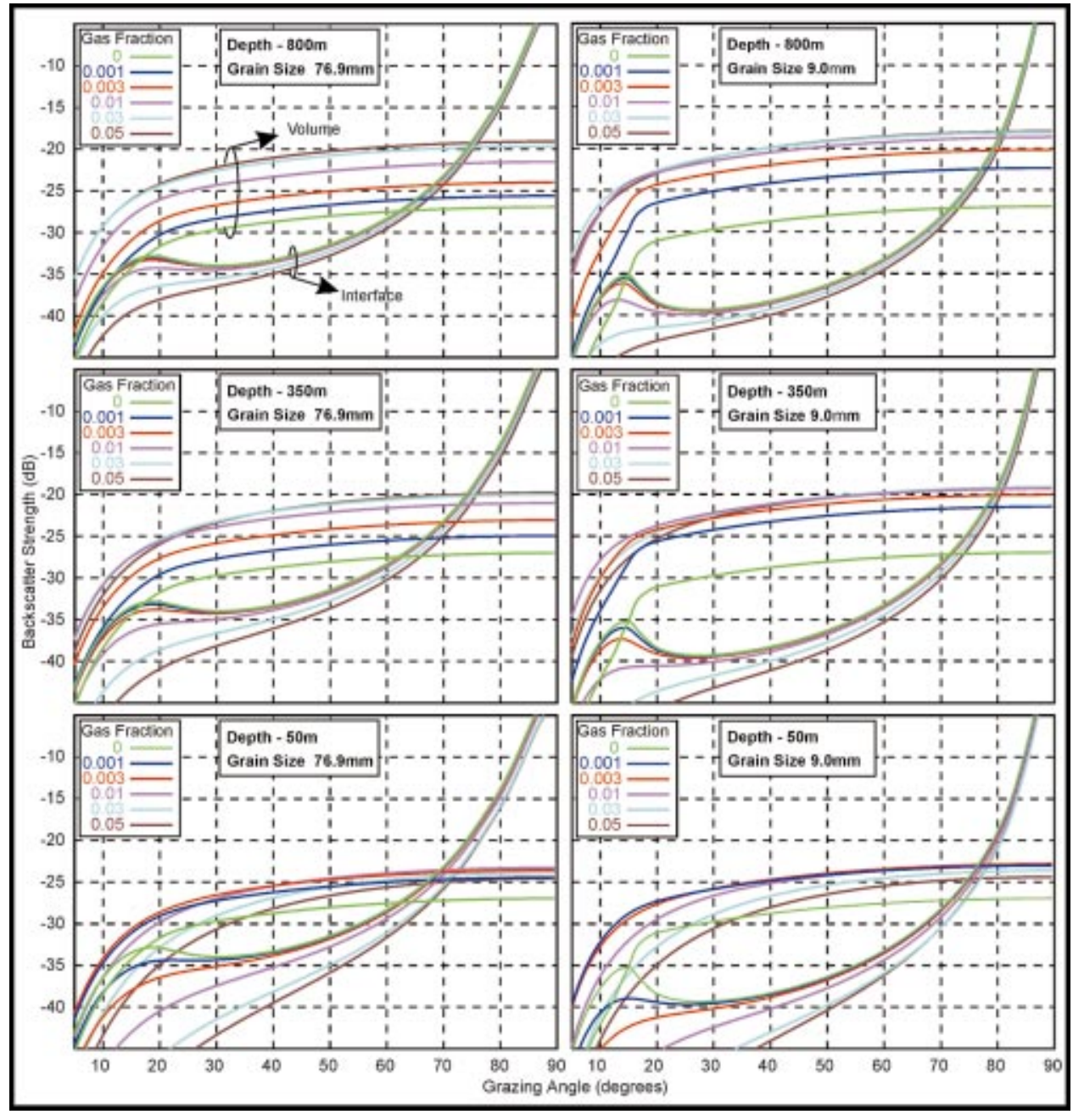

FIG. 2. Simulation of model results for two different grain sizes (columns) and three different depths (rows). The model response is calculated for various gas fractions ranging from 0 to $0.05(5 \%)$. Model parameters for grain size $76.9 \mu \mathrm{m}$ are $\nu=1.061, \rho=1.757$, $\delta=0.0193, \quad w_{2}=0.00136 \mathrm{~cm}^{4}, \quad \gamma$ $=3.25$, and $\sigma_{2}=0.001$, and for grain size $9.0 \mu \mathrm{m}$ are $\nu=1.039, \rho=1.664$, $\delta=0.00272, \quad w_{2}=0.00052 \mathrm{~cm}^{4}, \quad \gamma$ $=3.25$, and $\sigma_{2}=0.001$.

effects of local slope and shadowing (Jackson et al., 1986). The numerical solution for Eqs. (2) and (12) reveals a complex relationship involving grain size, depth, and gas fraction. In Fig. 2, the model response is calculated for various gas fractions using two different grain sizes (left and right columns of Fig. 2, respectively). The same computation is repeated for three different depths: 50, 350, and $800 \mathrm{~m}$ (rows of Fig. 2). The result of this modeling shows that the backscatter response of fine-grained, gassy sediments is basically controlled by the volume contribution, while coarser grain size sediments present both volume and interface backscatter contributions due to existence of gas.

In deeper waters, the interface backscatter is only slightly reduced by the presence of gas, as a consequence of the higher bubble stiffness at higher ambient pressure [Eq. (7)]. Bubble stiffness is defined as the product of the specific heat of the gas and the ambient pressure $\left(\gamma P_{0}\right)$. On the other hand, even small amounts of gas can cause a large increase in the volume contribution in deep water, i.e., increased scattering cross section [Eq. (12)]. In shallow waters, there is a severe reduction in interface backscatter with an increase in gas content. This is due to the decrease of sediment sound speed in the presence of gas below resonance (Anderson et al., 1998; Wilkens and Richardson, 1998). The volume backscatter contribution in shallow water increases with increased gas content but much less than the increases found in deep water, a result of the higher attenuation from the bubbles at lower ambient pressure (Fig. 2, bottom row). Thus, in shallow water, the gain in volume contribution is sometimes not enough to compensate for the loss in interface backscatter, yielding a net decrease in the total backscatter response.

Another interesting exercise is to calculate the model response for the range of seafloor roughness expected to be found in sediments of the Eel River Margin, that is $\omega_{2}$ from $0.00050 \mathrm{~cm}^{4}$ to $0.00200 \mathrm{~cm}^{4}$, and $\lambda$ equal to 3.25 (Applied Physics Laboratory, 1994). The result of this modeling shows that the backscatter response for grazing angles from 30 to 60 degrees of gassy sediments has a maximum increase of $1.2 \mathrm{~dB}$ when the seafloor roughness is changed from the minimum to the maximum value. On the other hand, the roughness parameters show a strong influence in the backscatter response in the angular sector near normal incidence i.e., grazing angles from 60 to 90 degrees. Thus, the backscatter angular response of gassy sediments in the angular sector from 30 to 60 degrees is less affected by seafloor roughness, and appears to be controlled by volume contribution.

\section{A TEST ON THE EEL RIVER MARGIN}

As a general test of the ideas outlined above we used multibeam sonar and core data collected from the Eel River 


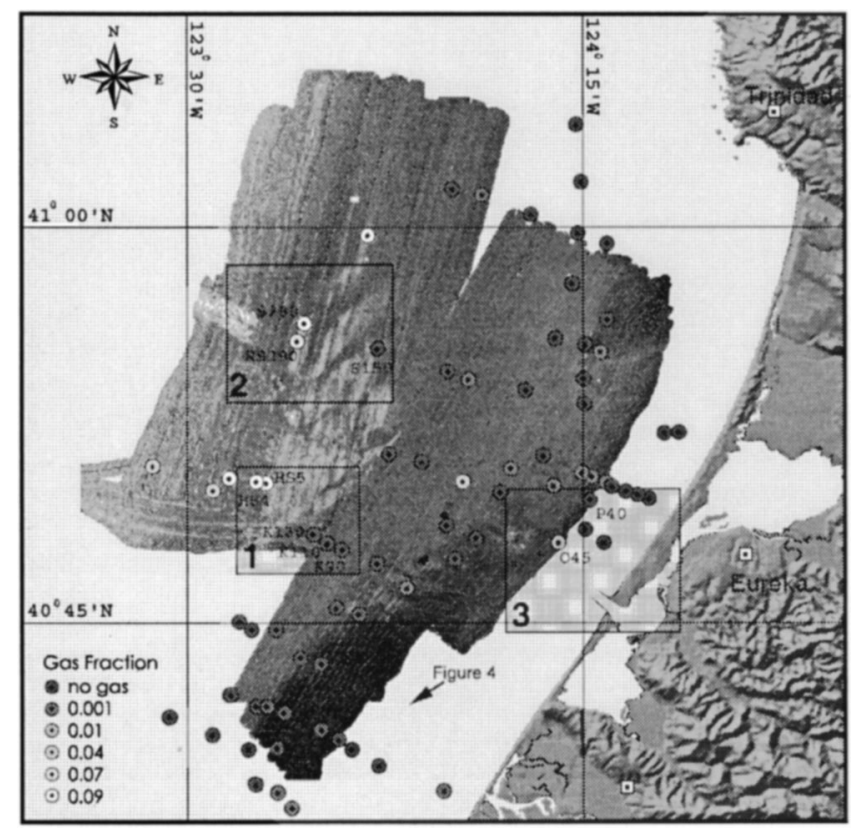

FIG. 3. Location map showing acoustic backscatter mosaics on the Eel River Margin from the EM1000 multibeam survey at $95 \mathrm{kHz}$. High backscatter is displayed in lighter shades of gray; low backscatter in darker tones. The brightness of the symbols is related to the amount of free gas in the sediment, as measured in core samples. The reference boxes demarcate the zoom areas for examples 1-3.

Margin offshore northern California, a region known to be rich in gassy sediments. The offshore Eel River Basin is located on the eastern border of the North American Plate, from Cape Mendocino extending $200 \mathrm{~km}$ northwards to Cape Sebastian, Oregon (Field et al., 1980). The eastern boundary of the basin is the coastline and the western boundary is the continental slope, which coincides with the crustal plate boundary of the Juan de Fuca Plate.

This margin was the focus of a multidisciplinary, 5-year ONR-sponsored study of the processes responsible for generating the preserved stratigraphic record (STRATAFORM; Nittrouer, 1998). In the course of this study, an immense database of marine information has been collected (Mayer et al., 1999), including multibeam sonar bottom backscatter collected at $95 \mathrm{kHz}$, and numerous core sampling sites with measurements of sediment physical properties and free gas content (Fig. 3).

The multibeam sonar data was collected with a Simrad EM1000, $95 \mathrm{kHz}$ system installed aboard the Humboldt State University research vessel PACIFIC HunTER. The EM1000 forms 60 roll stabilized $3.3 \times 2.5$-degree beams over a swath width of 150 degrees in water depths up to $200 \mathrm{~m}$. In deeper water, 48 beams are produced over a swath width of 120 degrees to about 600-m depth and 60 degrees beyond $600 \mathrm{~m}$. In addition to the bathymetric data, the EM1000 also provides raw measurements of the bottom backscatter as a function of grazing angle for each of the beams. All acquisition parameters are recorded and thus the raw data can be corrected for the removal of the time-varying gains, such as source level, receiver sensitivity, and angle-varying gains. Given that the detailed bathymetry is known from the multibeam time-of-flight measurements, true graz- ing angles with respect to a bathymetric model can be calculated as well as corrections for footprint size and residual beam pattern (Fonseca, 2001). Applying these corrections, the EM1000 backscatter data from the Eel River Margin was converted to true scattering strength for comparison with the results of the proposed model.

Interpreted much like sidescan sonar imagery (except with angular resolution), the backscatter mosaic of the Eel River Margin reveals several interesting spatial patterns (Fig. 3). A zone of extremely high backscatter (bright areas in Fig. 3 ) is found in the middle of the western (deep) edge of the survey area. The high backscatter in this region has been correlated with the outcrop of a large structural feature (a breached anticline) and blocky crusts of authigenic carbonate related to methane expulsion (Orange et al., 1999; Yun et al., 1999). The high-backscatter streaks in the middle of the survey area are thought to be associated with grain size changes and the outcrop of indurated sediment (Goff et al., 1999). More intriguing is the general trend of high backscatter in the deep water and low backscatter in shallow water, a relationship which is counter-intuitive when the general trend of grain size (decreasing from shallow water to deep water) is considered. This enigma was noted by Goff et al. (1999) and Borgeld et al. (1999), who suggest several possible mechanisms (increased surface roughness in finer grained sediments, increased penetration, and contribution of subsurface layering in finer-grained sediments) for this anomalous relationship. The complex relationship among gas content, water depth, and grain size described in the model presented here may offer another possible mechanism.

\section{A. Evidence for gas in the shallow sediments of the Eel River Margin}

The Eel River Basin is a tertiary forearc basin with conditions ideal for the generation and movement of both thermogenic and biogenic gas. Deep-seated source beds combined with differential sediment loading and a large amount of tectonic activity have resulted in overpressured zones and the migration of gas from deep layers to the surface and near-surface (Yun et al., 1999). In addition to the deep sources of gas, extremely high modern sedimentation rates and large quantities of organic material supplied by numerous floods provide an excellent source of biogenic gas (Summerfield and Nittrouer, 1999). Numerous lines of evidence support the ubiquitous presence of both thermogenic and biogenic gas in the sediments of the Eel River Margin. These include (1) observation of gas plumes in the water column (Yun et al., 1999); (2) direct measurements on cores (Kvenvolden and Field (1981) and this study (Orange, personal communication); (3) seismic evidence (wipeout zones and other acoustic anomalies), at a range of frequencies from low frequency multichannel seismic to high-frequency boomers, chirp sonars, and 3.5-kHz profilers (Field and Kvenvolden, 1987; Yun et al., 1999); (4) the presence of authigenic carbonates (Orange et al., 1999) and near-surface hydrates (Field and Kvenvolden, 1985); (5) towed electromagnetic surveys (Evans et al., 1999), (6) surface structures associated with 
gas (pockmarks and sediment failure features); and (7) commercial gas fields onshore with expected recovery of over $3.34 \mathrm{~km}^{3}$ of natural gas (Parker, 1987).

While there is overwhelming evidence for the presence of gas in the sediments of the Eel River Margin, the more pertinent question, with respect to testing the model proposed here, is whether there is evidence for gas in the upper few decimeters of the sediment column. Given the $95 \mathrm{kHz}$ frequency of the multibeam sonar used to survey the area, we would expect that penetration into, and interaction with, the subsurface would be limited to the upper few decimeters (to perhaps $1 \mathrm{~m}$ depending on sediment type and grazing angle). The near-surface distribution of gas is more difficult to quantify. Anderson et al. (1998) in their study of Eckernfoerde Bay noted that the gas bubbles they were able to measure (those greater than $0.42 \mathrm{~mm}$ equivalent spherical radius) were not present in the upper few decimeters of the sediment column due to sulfate reduction. They do, however, report that cores recovered from another bay (Macklenberg Bay) did show small gas bubbles in the upper $2 \mathrm{~cm}$ of the sediment column and that frequency-dependent reflectivity data from Eckernforde Bay implied the presence of very small bubbles in the upper few centimeters of the seafloor.

Several lines of evidence (both indirect and direct) imply that gas may be present in the upper few decimeters of the sediments of the Eel River Margin. Unlike Eckernfoerde Bay, which is a semi-inclosed fjord-like bay with bottom waters that often experience hypoxia and occasionally anoxia and whose gas source is strictly biogenic (Richardson and Davis, 1998), the Eel River Basin is an open ocean continental margin environment with well-mixed water masses and both thermogenic and biogenic sources of gas. Highresolution $3.5 \mathrm{kHz}$, boomer, and chirp sonar data all show regions of "wipeout zones" (acoustic turbidity), some of which extend to the surface and even into the water column (Field and Kvenvolden, 1987; Yun et al., 1999; and Fig. 4). In addition reduced halos and mats of the sulfate oxidizing bacterium Beggiatoa $s p$ have been seen on the seafloor in areas of the Eel River Margin (Orange, 1999) indicating the slow seepage of methane to the seafloor. Further evidence for near-surface gas is provided by Evans et al. (1999) who made resistivity measurements using a towed electromagnetic sensor and interpreted low apparent porosities to indicate the presence of gas in the upper few meters of the sediment column, particularly in the shallow water regions of the Eel River Margin, which showed anomalously low backscatter.

Direct evidence of the presence of shallow gas in the Eel River Margin comes from the analysis of gas content in shallow cores. Kvenvolden and Field (1981) analyzed 1- to 2-mlong gravity cores from a diapiric structure in the deeper waters of the Eel River basin $(400-500 \mathrm{~m})$ and found high concentrations of methane (both biogenic and thermogenic) throughout the cores including samples from depths as shallow as 6-14 cm below the seafloor. As part of the STRATAFORM project, hundreds of cores were collected in the Eel River Basin, with some showing visual evidence of gas (Borgeld et al., 1999); a small number of these cores were analyzed for gas content. A subset of those analyzed,

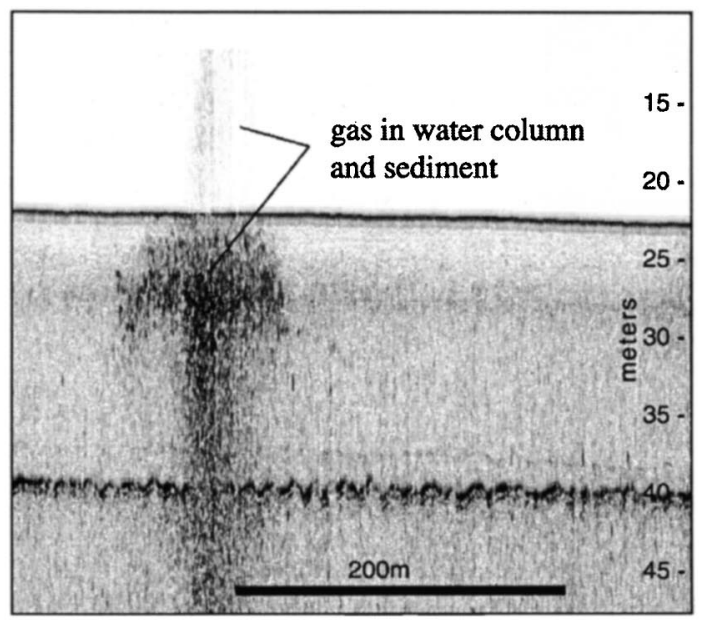

(a)

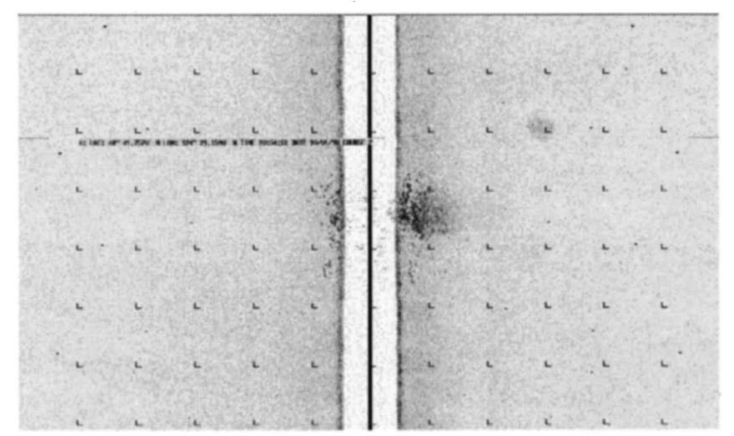

(b)

FIG. 4. Evidence that gas may be present in shallow sediments of the Eel River Margin: (a) High-resolution 3.5-kHz chirp profile, showing a region of acoustic turbidity, which extends to the surface and into the water column. (b) Same area surveyed by a $100-\mathrm{kHz}$ sidescan sonar. See Fig. 3 for location. Source: Neal Driscoll.

representing multiple samples from areas of differing backscatter, depth, and gas content are used here to test the proposed model. The areas and core sites selected are shown in Fig. 3.

The core data presented here were collected by Dan Orange on the University of Washington research vessel ThOMAs ThOMPSon (Cruise TN096) in 1999. During this leg, several types of cores were collected including Vibracores, piston cores, and box cores; core lengths ranged from more than $5 \mathrm{~m}$ to less than $25 \mathrm{~cm}$. Analysis of gas content followed the procedure of Kvenvolden and Redden (1980), whereby sediment is taken immediately after core recovery from an approximately $10 \mathrm{~cm}$ interval of the core (typically about $10 \mathrm{~cm}$ above its base). The sediment is extruded from the core liner into a 0.951 can with two septa-covered holes on the top. Sodium azide is added to the sample and the water level adjusted until a $100 \mathrm{ml}$ headspace remains. The samples are then sealed and frozen for later analysis in the lab. In the laboratory, the samples are thawed and shaken for $10 \mathrm{~min}$ and the headspace sampled by syringe for hydrocarbon gases. Analyses were performed on an HP gas chromatograph with both flame ionization and thermal conductivity detectors.

It must be noted that while these analyses are indicative 
TABLE I. Physical properties measured at selected core sites.

\begin{tabular}{lrrrrrrr}
\hline \hline & $\begin{array}{c}\text { Grain } \\
\text { size } \\
(\mu \mathrm{m})\end{array}$ & $\begin{array}{c}\text { Sound } \\
\text { speed } \\
(\mathrm{m} / \mathrm{s})\end{array}$ & $\begin{array}{c}\text { Density } \\
\left(\mathrm{kg} / \mathrm{m}^{3}\right)\end{array}$ & $\begin{array}{c}\text { Water } \\
\text { depth } \\
(\mathrm{m})\end{array}$ & $\begin{array}{c}\text { Gas } \\
\text { fraction }\end{array}$ & $\begin{array}{c}\text { Gas } \\
\text { content }\end{array}$ & Site \\
\hline HS4 & 9.0 & 1552 & 1786 & 318 & 0.0954 & V. High & 1 \\
HS5 & 9.0 & 1553 & 1809 & 320 & 0.0951 & V. High & 1 \\
K130 & 9.0 & 1543 & 1701 & 125 & 0.0 & None & 1 \\
K110 & 16.7 & 1544 & 1696 & 114 & 0.0 & None & 1 \\
K90 & 16.7 & 1545 & 1690 & 104 & 0.0 & None & 1 \\
S280 & 9.6 & 1583 & 1800 & 258 & 0.075 & High & 2 \\
RS290 & 9.6 & 1583 & 1800 & 267 & 0.067 & High & 2 \\
S150 & 13.6 & 1567 & 1794 & 151 & 0.0 & None & 2 \\
O45 & 76.9 & 1575 & 1796 & 39 & 0.01 & Low & 3 \\
P40 & 125.0 & 1560 & 1784 & 40 & 0.0 & None & 3 \\
\hline \hline
\end{tabular}

of the presence, absence, and perhaps relative abundance of gas at a sample location, they do not provide an accurate measure of the in situ abundance of free gas in the sample, and in particular, in the upper decimeters of the seafloor. Thus, while we report the measured value in Table I, we will use these values only as indicators of the relative gas content of the seafloor sediments. In addition to the gas content, the mean grain size, sound speed, and saturated bulk density of the sediment were also measured on the core samples. These data are presented in Table I and are used as inputs into the model presented above. There are no available measurements for the sediment roughness and compressional wave attenuation for the studied sites. For these values, a parametrization in terms of the bulk grain size was used following the method described in the APL-UW High-Frequency Ocean Environment Acoustic Models Handbook (Applied Physics Laboratory, 1994).

Although it would be better to have the full grain size distribution in order to explain backscattering differences due to physical properties, only the mean grain size was available for the core sites. The parameter $\sigma_{2}$ cannot be directly measured, and one average value (0.01) was used (Applied Physics Laboratory, 1994). This assumption can lead to an overestimate of the effect of gas bubbles, because $\sigma_{2}$ is a measurement of sediment heterogeneities other than gas. Fortunately, the effect scattering contribution of gas bubbles is normally many times higher than the contribution of other scatterers, making the use of a constant $\sigma_{2}$ an acceptable assumption. Another factor that would increase the volume contribution is the presence of multiple scattering (Jackson and Ivakin, 1998). Table II shows values of physical parameters that are common for all four examples. The model was

TABLE II. Values of common parameters used to evaluate the model at selected sites $\mathrm{A}, \mathrm{B}, \mathrm{C}$, and D.

\begin{tabular}{lll}
\hline \hline Seawater density & $\rho_{w}$ & $1022 \mathrm{~kg} / \mathrm{m}^{3}$ \\
Seawater sound speed & $c_{w}$ & $1485 \mathrm{~m} / \mathrm{s}$ \\
Gas density & $\rho_{g}$ & $1.24 \mathrm{~kg} / \mathrm{m}^{3}$ \\
Gas ratio of specific heats & $\gamma$ & 1.403 \\
Gas specific heat at constant pressure & $s_{p}$ & $240 \mathrm{cal} / \mathrm{kg}$ \\
Gas thermal conductivity & $C_{g}$ & $5.6 \times 10^{-3} \mathrm{cal} /\left(\mathrm{m} \mathrm{s}^{\circ} \mathrm{C}\right)$ \\
Muddy sediment viscosity & $\mu$ & $1.0 \times 10^{-3} \mathrm{~kg} /\left(\mathrm{m} \mathrm{s}^{2}\right)$ \\
Ambient hydrostatic pressure & $P_{0}$ & $\left(1.0135 \times 10^{5}\right.$ \\
& & $\left.+9.80665^{*} \rho_{\mathrm{w}} * \mathrm{depth}\right) \mathrm{N} / \mathrm{m}^{2}$ \\
\hline \hline
\end{tabular}

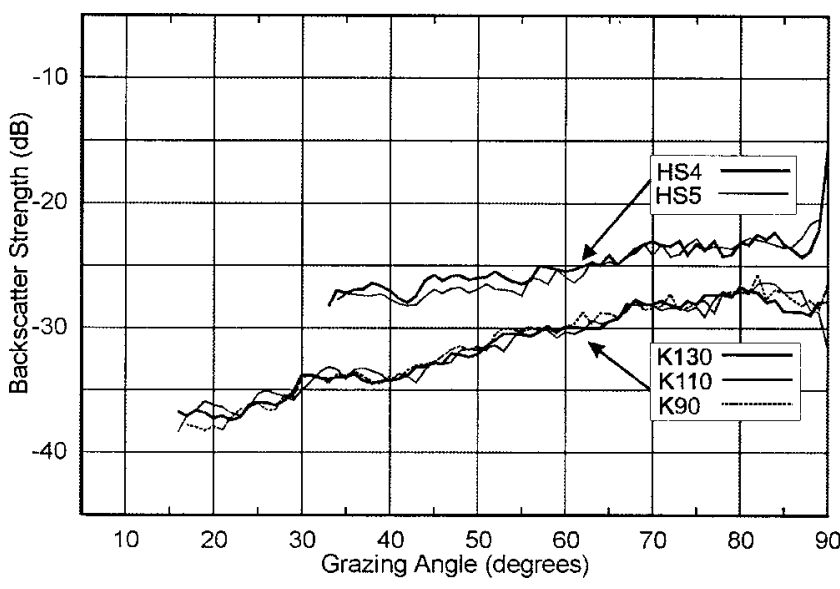

FIG. 5. Backscattering strength measured by a Simrad EM1000 multibeam sonar $(95 \mathrm{kHz})$ around core sites HS4, HS5, K90, K110, and K130.

run for each core site using the parameters presented in Tables I and II; these results as well as comparisons to the measured multibeam sonar backscatter in the area will be discussed in the next section.

\section{B. Area 1 (Humboldt Slide) mid-depth range}

Area 1 (Fig. 3) encompasses five core locations, which have variable gas fractions and associated backscatter. Cores HS-4 and HS-5 have high gas fractions: 0.0951 and 0.0980, respectively. The average depth for these two cores is $330 \mathrm{~m}$. Cores K90, K110, and K130, on the other hand, have no measured gas; their average depth is $114 \mathrm{~m}$. Backscatter images from a SIS-1000 deep-towed sidescan sonar reveal a dense distribution of pockmarks through this area (the Humboldt Slide zone), providing evidence for widespread, but focused, gas and fluid venting (Gardner et al., 1999). Figure 5 shows the backscattering strength measured at these core sites by the EM1000 multibeam sonar. The displayed curves are an average of 50 sonar pings around the core sites, which represents on average a linear distance of $100 \mathrm{~m}$. There is a $5 \mathrm{~dB}$ difference in the backscatter response (average backscatter for grazing angles from 30 to 60 degrees) between sites with and without measured gas. This difference cannot be explained by the differences in physical properties measured at these five core sites (Tables I and II).

The backscatter angular response can be calculated using sediment properties measured at the core sites (Table I). The parameters used as input for the model are $\nu=1.039$, $\rho=1.664, \delta=0.00272, w_{2}=0.00052 \mathrm{~cm}^{4}, \quad \gamma=3.25$, and $\sigma_{2}=0.0010$, with no gas. The result is shown in Fig. 6 for the interface backscatter and the total (volume+interface) backscatter. The model was then run a second time, including the very high gas fraction of 0.098 , which changed the following model parameters: $\nu=0.939, \rho=1.571$, and $\delta$ $=0.0695$, and generated an equivalent volume contribution of $\sigma_{2}=0.0068$ (including contributions from gas and other heterogeneities). Note that the model shows about $6 \mathrm{~dB}$ difference (average backscatter for grazing angles from 30 to 60 degrees) between sites with high gas content and those with no measured gas, which is similar to what is shown in Fig. 5. The difference in absolute values between data and model 


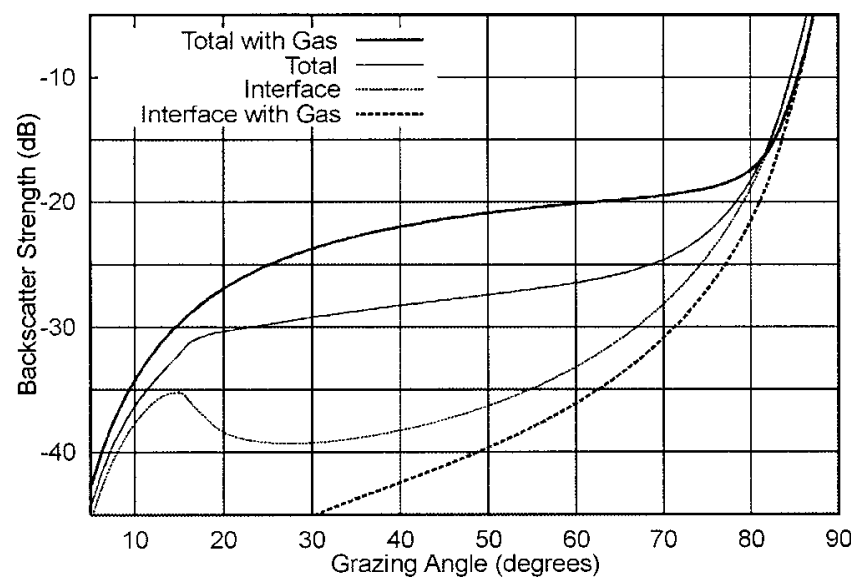

FIG. 6. Model response using the sediment properties measured at the core sites HS4, HS5, K90, K110, and K130.

(Figs. 5 and 6) is small, which may be explained by calibration problems in multibeam sonar systems. There was a small reduction of interface backscatter due to the low sound speed ratio of the gassy sediment. The volume backscatter of the gassy sediment is considerably higher, which results in a net increase in the backscatter response.

\section{Area 2 (mid-depth range)}

Area 2 (Fig. 3) contains cores S280 and RS290 which have moderately high gas fractions: 0.075 and 0.067 , respectively. These two cores are located at an average depth of $253 \mathrm{~m}$. Core S150 at $151 \mathrm{~m}$ of depth has no measured gas. The existence of near-surface gas in this area is demonstrated by acoustic anomalies on Huntec seismic profiles (Yun et al., 1999). Figure 7 shows the backscattering strength measured at these core sites by the EM1000 multibeam sonar. The final response is an average of 50 sonar pings around the core sites. There is an average of $4 \mathrm{~dB}$ difference in the backscatter response between sites with and without measured gas, although the sites have basically the same sediment properties.

Figure 8 shows the model response using the sediment properties measured at the core sites (Table I) and the common values in Table II. The parameters used as input for the

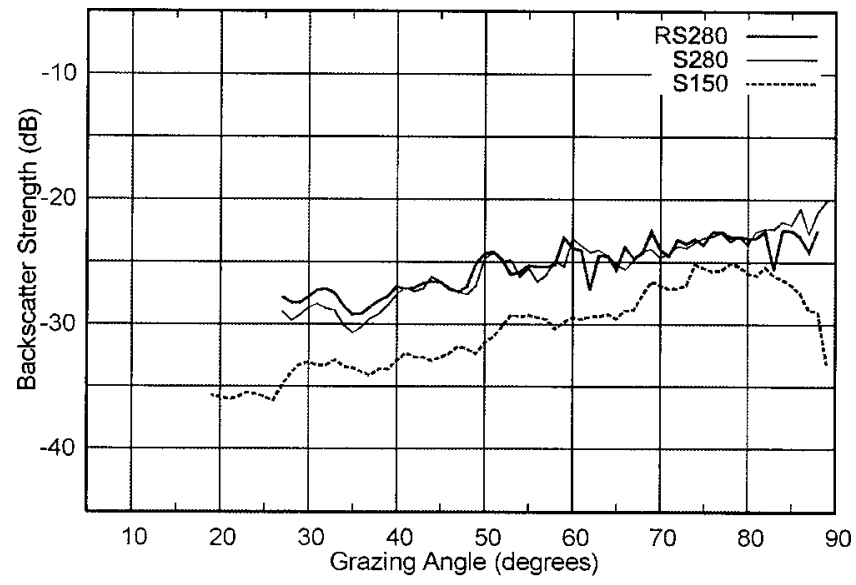

FIG. 7. Backscattering strength measured by a Simrad EM1000 multibeam sonar $(95 \mathrm{kHz})$ around core sites RS280, S280, and S150.

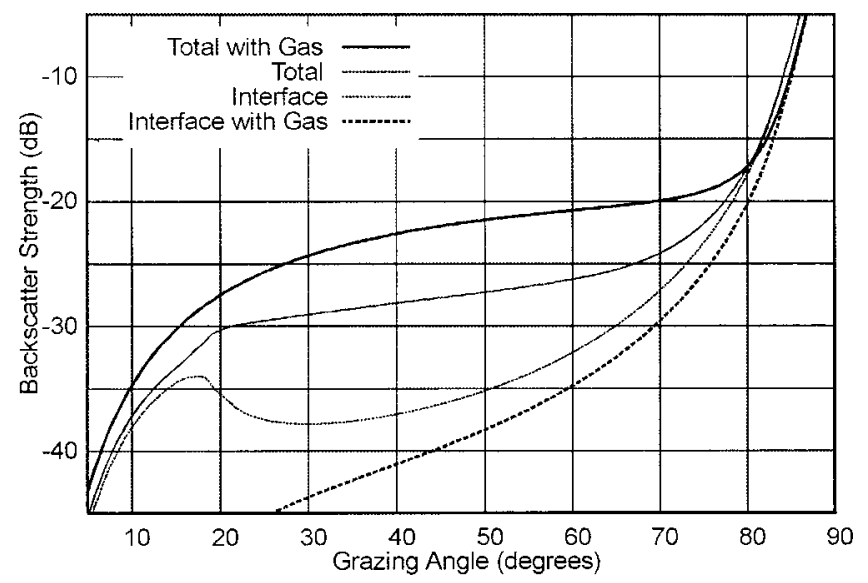

FIG. 8. Model response using the sediment properties measured at the core sites RS280, S280, and S150.

model are $\nu=1.0552, \quad \rho=1.755, \quad \delta=0.00290, \quad w_{2}$ $=0.00052 \mathrm{~cm}^{4}, \gamma=3.25$, and $\sigma_{2}=0.001$, with no gas. The model was run a second time including the moderately high gas fraction of 0.075 , which changed the following model parameters: $\nu=0.972, \rho=1.683$, and $\delta=0.0532$, and generated an equivalent volume contribution of $\sigma_{2}=0.0055$ (including contributions from gas and other heterogeneities). Note that the model predicts a $4 \mathrm{~dB}$ increase in backscatter strength when gas is included and that this is consistent with the difference seen in the measured backscatter between gassy (RS280 and S280) and non-gassy (S150) sites (Fig. 7). At these depths (336 m for Area 1 and $252 \mathrm{~m}$ for Area 2) the presence of gas has the effect of slightly lowering the interface backscattering component and significantly increasing the volume backscattering component.

\section{Area 3 (shallow water)}

Area 3 (Fig. 3) contains two core locations in relatively shallow water $(39 \mathrm{~m})$. Core $\mathrm{O} 45$ had a measured gas fraction of 0.010 , while core P40 had no measured gas. These two cores are also inside the zone of acoustic turbidity, interpreted from high-frequency seismic profiles, to be caused by the presence of gas (Yun et al., 1999). Figure 9 shows the backscattering strength measured at these two core sites by

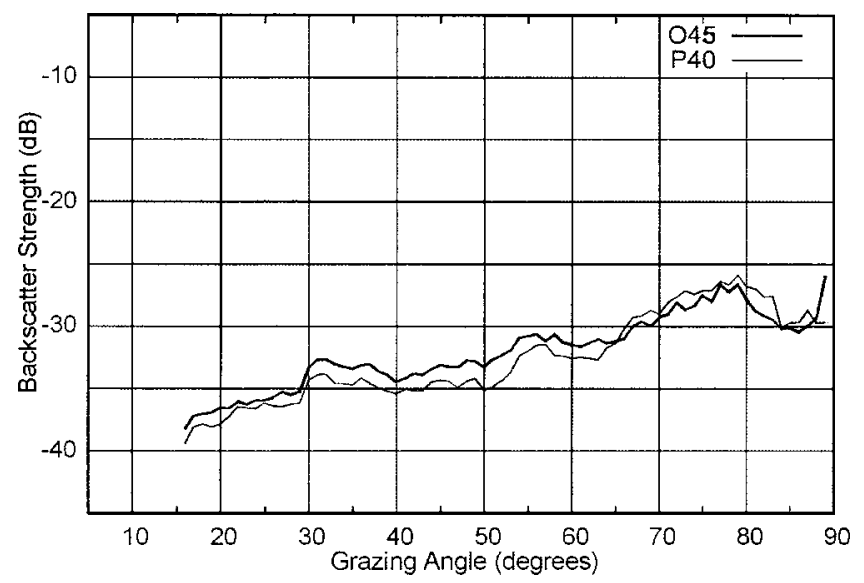

FIG. 9. Backscattering strength measured by a Simrad EM1000 multibeam sonar $(95 \mathrm{kHz})$ around core sites $\mathrm{O} 45$ and $\mathrm{P} 40$. 


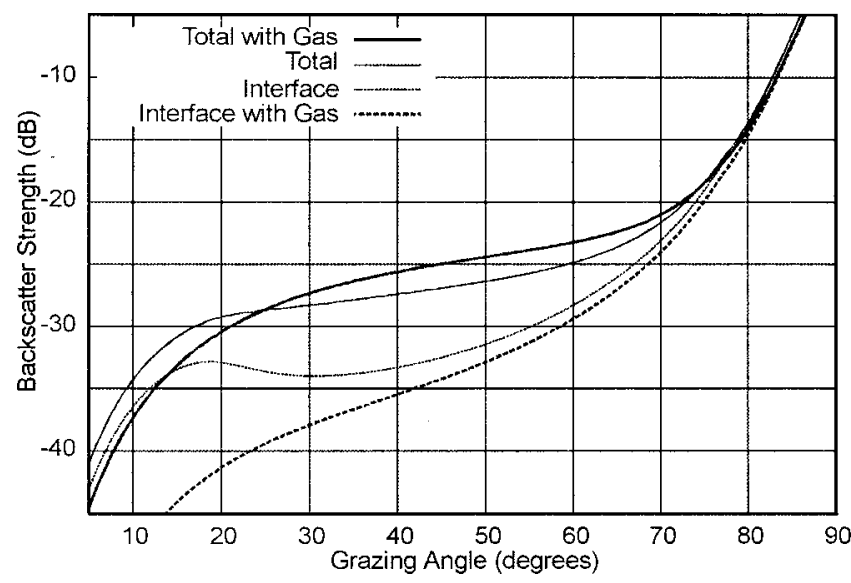

FIG. 10. Model response using the sediment properties measured at the core sites $\mathrm{O} 45$ and $\mathrm{P} 40$.

the Simrad EM1000 multibeam sonar. There is almost no difference at the backscatter strength between the sites.

The model response is calculated using the sediment properties measured at the core sites and common values of Table II. The parameters used as input for the model are $\nu$ $=1.061, \quad \rho=1.757, \quad \delta=0.01972, \quad w_{2}=0.00120 \mathrm{~cm}^{4}, \quad \gamma$ $=3.25$, and $\sigma_{2}=0.0010$, with no gas. The model was run a second time including the low gas fraction of 0.01 , which changed the following model parameters: $\nu=0.891, \rho$ $=1.747$, and $\delta=0.0768$, and generated an equivalent volume contribution of $\sigma_{2}=0.0011$ (including contributions from gas and other heterogeneities). When gas is added, the model predicts a very small difference between the two sites (Fig. 10). In shallow water $(39 \mathrm{~m})$ there is a severe reduction of interface backscatter due to the very low sound speed ratio of the gassy sediment. The increase in volume backscatter of the gassy sediment is not high enough to compensate for the interface backscatter reduction. This relatively small volume scatter is a consequence of the higher attenuation of gassy sediment in shallow water. In shallow water, the ambient pressure is lower, which increases the attenuation in the gassy sediment, according to Eq. (9).

\section{CONCLUSIONS}

Gas is an important and common sediment heterogeneity on continental margins which may explain some of the backscatter-response anomalies seen in the sediments on the Eel River Margin. A model has been proposed that shows that gas affects both the interface and volume contribution of the backscatter angular response. Gas normally increases the volume contribution and weakens the interface contribution, but the relationship is complicated by changes in depth and sediment properties. The backscatter response of fine-grained gassy sediments (grain size $<10 \mu \mathrm{m}$ ) is basically controlled by the volume contribution to backscattering. Coarser sediments (grain size $>60 \mu \mathrm{m}$ ) present both significant changes in volume and interface backscatter in the presence of gas.

The model was tested by inputting physical properties measured on cores collected in a region also surveyed with a $95 \mathrm{kHz}$ multibeam sonar. The cores selected for input into the model were cores that had also been analyzed for gas content and these values were used to estimate the relative abundance of gas at the core sites. While the head-space analyses used for determining gas content are not necessarily an accurate representation of the in situ concentration of free gas in the cores, they are indicative of the presence, absence and perhaps relative abundance of gas in the upper few meters of the seafloor. Both the gas measurements and the multibeam backscatter showed a high degree of lateral variability.

Raw time series of the $95 \mathrm{kHz}$ multibeam sonar backscatter as a function of angle of incidence were corrected for source and receiver gain changes, area of insonification, true grazing angle, and residual beam patterns resulting in a georeferenced record of true scattering strength. The measured backscatter (averaged over about $100 \mathrm{~m}$ around each core site) was then compared to the model output for each core site and for a range of gas contents. The measured results were generally in agreement with the model and with the results predicted for the measured gas contents.

Depth plays an important role in the backscatter response of gassy sediments. In deep water (deeper than 400 $\mathrm{m})$, the predicted interface backscatter is only slightly affected by the presence of gas, a consequence of the higher bubble stiffness at higher ambient pressure. On the other hand, a small amount of gas yields a very-high predicted volume contribution in deep water. In shallow water (less than $100 \mathrm{~m}$ ), the predicted interface backscatter is severely reduced when the sediment is charged with free gas, due to the decrease of sediment sound speed. The predicted volume contribution in shallow water is lower, due to higher attenuation from the bubbles at lower ambient pressure. In shallow water, the gain in volume contribution is sometimes not enough to compensate for the loss in interface backscatter, resulting in a net decrease in the total backscatter response.

While the results presented here are encouraging in terms of the potential for using multibeam sonar as a qualitative and quantitative indicator of the gas content of nearsurface sediments, much more work needs to be done. In particular, the model needs to be tested under controlled conditions where near-surface sediment samples can be collected and maintained under in situ conditions (as described in Anderson et al., 1998). New developments in pressuremaintaining core barrels (e.g., Pettigrew, 1992) should greatly aid in this effort. In addition, the models need to be extended to include the effect of multiple scattering, which should provide a more accurate prediction of the total scattering due to gas bubbles.

\section{ACKNOWLEDGMENTS}

This study was made possible by funding from the Office of Naval Research Contract No. N00014-00-1-0092. Special thanks for Janet Yun for the Eel Shelf data that she provided. The authors express their appreciation to Brian Calder for all the valuable suggestions and the support with the model programming.

Anderson, A., Abegg, F., Hawkins, J. A., Duncan, M. E., and Lyons, A. P. (1998). "Bubble populations and acoustic interaction with the gassy floor of Echernförde Bay,” Continental Shelf Res. 18, 1807-1838. 
Anderson, A., and Hampton, L. D. (1980a). "Acoustics of gas-bearing sediments I. Background," J. Acoust. Soc. Am. 67, 1865-1889.

Anderson, A., and Hampton, L. D. (1980b). "Acoustics of gas-bearing sediments II. Measurements and models," J. Acoust. Soc. Am. 67, 1890-1903. Applied Physics Laboratory. (1994). High-Frequency Ocean Environmental Acoustic Models Handbook, Applied Physics Laboratory Technical Report APL-UW TR 9407, University of Washington, Seattle, WA, Chap. 4.

Borgeld, J. C., Clarke, J. E. Hughes, Goff, J. A., Mayer, L. A., and Curtis, J. A. (1999). "Acoustic backscatter of the 1995 flood deposit on the Eel shelf," Mar. Geol. 194, 183-196.

Boyle, F. A., and Chotiros, N. P. (1995). "A model for high-frequency acoustic backscatter from gas bubbles in sandy sediments at shallow grazing angles," J. Acoust. Soc. Am. 98, 531-541.

de Moustier, C., and Alexandrou, D. (1991). "Angular dependence of 12 kHz Seafloor Acoustic Backscatter," J. Acoust. Soc. Am. 90, 522-531.

Evans, R. L., Law, L. K., St. Louis, B., Cheesman, S., and Sananikone, K. (1999). "The shallow porosity structure of the Eel shelf, northern California: results of a towed electromagnetic survey," Mar. Geol. 154, 211-226.

Farmer, D. M., and Vagle, S. (1989). "Waveguide propagation of ambient sound in the ocean-surface bubble layer," J. Acoust. Soc. Am. 86, 18971908.

Field, M. S., and Kvenvolden, K. A. (1985). "Gas hydrates on the northern California continental margin," Geology 13, 517-520.

Field, M. S., and Kvenvolden, K. A. (1987). "Preliminary report on gaseous hydrocarbons in sediments and seeps offshore Eel River basin, California," in Tectonics, Sedimentation and Evolution of the Eel River Basin and Other Coastal Basins of Northern California, edited by H. Schymiczek and R. Suchsland, San Joaquin Geological Society Miscellaneous Publication, Vol. 37, pp. 55-60.

Field, M. S., Clarke, H., and White, M. E. (1980). "Geology and geologic hazards of offshore Eel River Basin, Northern California Continental Margin," USGS Open-file report 80-1080.

Fonseca, L. (2001). "A model for backscattering angular response of gassy sediments: Applications to petroleum exploration and development programs," Ph.D. Thesis, Ocean Engineering, University of New Hampshire.

Gardner, J. V., Prior, D. B., and Field, M. E. (1999). "Humboldt Slide-a large shear-dominated retrogressive slope failure," Mar. Geol. 154, 323 338 .

Goff, J. A., Orange, D. L., Mayer, L. A., and Hughes Clarke, J. E. (1999). "Detailed investigation of continental shelf morphology using a highresolution swath sonar survey: the Eel margin, northern California," Mar. Geol. 154, 255-270.

Hovland, M., and Judd, A. G. (1989). Seabed Pockmarks and Seepages: Impact on Geology, Biology and the Marine Environment (Graham \& Trotman, Norwell, MA).

Ivakin, A. N. (1998). "A unified approach to volume and roughness scattering," J. Acoust. Soc. Am. 103, 827-837.

Jackson, D. R., and Briggs, K. B. (1992). "High-frequency bottom backscattering: Roughness versus sediment volume scattering," J. Acoust. Soc. Am. 92, 962-977.

Jackson, D. R., Winebrenner, D. P., and Ishimaru, A. (1986). "Application of the composite roughness model to high-frequency bottom backscattering," J. Acoust. Soc. Am. 79, 1410-1422.
Jackson, D. R., and Ivakin, A. N. (1998), "Scattering from elastic sea beds: First-order theory," J. Acoust. Soc. Am. 103, 336-345.

Kvenvolden, K., and Field, M. (1981). "Thermogenic hydrocarbons in unconsolidated sediment of Eel River Basin, Offshore Northern California," AAPG Bull. 65, 1642-1646.

Kvenvolden, K. A., and Redden, G. D. (1980). "Hydrocarbon gas in sediment from the shelf, slope and basin of the Bering Sea," Geochim. Cosmochim. Acta 44, 1145-1150.

Lyons, A. P., Duncan, M. E., Anderson, A. L., and Hawkins, J. A. (1996). "Predictions of the acoustic scattering response of free-methane bubbles in muddy sediments." J. Acoust. Soc. Am. 99, 163-172.

Mayer, L., Fonseca, L., Pacheco, M., Galway, S., Martinez, J. V., and Hou, T. (1999). "The STRATAFORM GIS CD," U.S. Office of Naval Research distribution.

Mourad, P. D., and Jackson, D. R. (1989), "High frequency sonar equation models for bottom backscatter and forward loss," in Proceedings of OCEANS'89 (IEEE, New York), pp. 1168-1175.

Nittrouer, C. A. (1998). "STRATAFORM: Overview of its design and synthesis of its results," Mar. Geol. 154, 3-12.

Novarini, J. C., and Caruthers, J. W. (1998). "A simplified approach to backscattering from a rough seafloor with sediment inhomogeneities," J. Ocean. Eng. 23(3), 157-166.

Orange, D. L. (1999). "Tectonics, sedimentation, and erosion in northern California: submarine geomorphology and sediment preservation potential as a result of three competing process," Mar. Geol. 154, 368-382.

Orange, D. L., Angell, M., and Lapp, D. (1999). "Applications of multibeam mapping to exploration and production: Detecting seeps, mapping geohazards, and managing data overload with GIS," The Leading Edge, 18, 495-501.

Parker, J. D. (1987). "Geology of the Tompkins Hill gas field, Humboldt County, California," in Tectonics, Sedimentation and Evolution of the Eel River Basin and Other Coastal Basins of Northern California, edited by H. Schymiczek and R. Suchsland, San Joaquin Geological Society Miscellaneous Publication, Vol. 37, pp. 83-88.

Pettigrew, T. L. (1992). "The design and operation of a wireline pressure core sampler (PCS)," ODP Tech. Note 17.

Richardson, M. D., and Davis, A. M. (1998). "Modeling methane-rich sediments of Eckernförde Bay," Continental Shelf Res. 18(14-15), 16711688 .

Silberman, E. (1957). "Sound velocity and attenuation in bubbly mixtures measured in standing wave tubes," J. Acoust. Soc. Am. 29, 925-953.

Stockhausen, J. H. (1963). "Scattering from the Volume of an Inhomogeneous Half-Space," Naval Research Establishment, Canada, Report 63/9.

Summerfield, C. K., and Nittrouer, C. A. (1999). "Modern accumulation rates and a sediment budget for the Eel shelf: a flood dominated depositional environment," Mar. Geol. 154, 227-242.

Wilkens, R. H., and Richardson, M. D. (1998). "The influence of gas bubbles on sediment acoustic properties: in situ, laboratory, and theoretical results from Eckernfoerde Bay, Baltic Sea," Continental Shelf Res. 18, $1859-1892$.

Yun, W. J., Orange, D. L., and Field, M. E. (1999). "Subsurface Gas Offshore Northern California and its Link to Submarine Geomorphology," Mar. Geol. 154, 357-368. 